tually was. Moreover, though many of the documents represent the reporting of events and experiences as they took place, they also reflect the positionality, and purpose of the author and the intended audience. Subjectivity and bias will also influence the validity of the information conveyed and used for constructing climatic chronologies. It is difficult to establish from documentary sources, for instance, what constituted normal climatic conditions. There may also be some cases (for example during political upheavals) when unusual climate goes unreported in either the documentary or instrumental record. Whether a climate event is recorded is also dependent on the size of the potentially affected population and its level of economic development.
Climatically-induced agricultural failure, for instance, is only likely to be recorded if a significant number of people are affected by harvest losses. It is also likely that the frequency of singular events might be relatively under recorded in comparison with recognised severe climatic phases, where bad conditions persist over several years.

Such interpretative problems can compromise the value of archival records of climate change. The collections of historical documents available for Latin America as a whole are extremely rich and diverse. Used carefully, these archives can provide us with an invaluable and as yet still under-exploited medium for the reconstruction of detailed regional climate histories.

\section{REFERENCES}

Butzer, K.W. and Butzer, E.K., 1997: The 'natural' vegetation of the Mexican Bajio: archival documentation of a 16th-century savanna environment. Quaternary International 43/44, 161-172.

Endfield, G.H. and O'Hara, S.L., 1997: Conflicts over water in 'The Little Drought Age' in Central Mexico. Environment and History 3, 255-272.

Florescano, E. and Swan. S., 1995: Breve historia de la sequía en México. Universidad Veracruzana, Xalapa.

O'Hara, S.L. and Metcalfe, S.E., 1995: Reconstructing the climate of Mexico from historical records. The Holocene 5, 485-490.

Prieto, M., R. Herrera and Dussel, P., 2000: Archival evidence for some aspects of historical climate variability in Argentina and Bolivia during the 17th and 18th centuries. In: Southern Hemisphere Paleoand Neoclimates. W. Volkheimer and P. Smolka (eds). Springer -Verlag, Berlin-Heidelberg, $381 \mathrm{p}$.

Quinn, W.H., V.T. Neal and Antúnez de Mayolo., S., 1987: El Niño occurrences over the past four and a half centuries

\title{
ENSO Reconstruction Based on Documentary Data From Ecuador, Peru and Chile
}

\author{
Luc 0rtlieb 1 , Gabriel Vargas ${ }^{2}$ and AnNe-Marie Hocouenghem 3 \\ 1 UR PALEOTROPIOUE, IRD, Bondy (France); Luc.Ortlieb@bondy.ird.fr \\ ${ }^{2}$ Depto. de Geología, Universidad de Chile \& UR PALEOTROPIQUE, Santiago (Chile); gvargas@ing.uchile.cl \\ ${ }^{3}$ CNRS \& IRD, Institut Français d'Etudes Andines, Lima (Peru); amhocquenghem@terra.com.pe
}

The first chronology of ENSO occurrences in the past centuries was based on documentary data from South America. A review of the sources and a closer look at the geographical distribution of ENSO impacts across the subcontinent revealed that the sequences of $\mathrm{El}$ Niño events previously proposed (Quinn, 1987) should not be used for calibration purposes until a better knowledge of the regional impacts of ENSO is obtained. On-going research on documentary sources from central Chile and Peru suggests that the current teleconnection patterns were different prior to the early $19^{\text {th }}$ century. If correct, this hypothesis may have important consequences for understanding multidecadal and century-scale ENSO dynamics.

\section{Quinn's historical sequence of El Niño events}

The El Niño phenomenon was defined in 1891, in northern Peru, as a combination of anomalously warm sea temperature, stronger than usual southward coastal current and high rainfall in the Sechura desert. In successive works (Quinn et al., 1987;
Quinn \& Neal, 1992; Quinn, 1993), Quinn proposed a chronological sequence of EI Niño events, covering the last $41 / 2$ centuries, with an individual strength evaluation and confidence rating of every episode. In his last reconstructions, Quinn incorporated more data from Chile and Brazil than from Peru. In his last published work (1993), he also considered a series of documentary and hydrological proxies from the western Pacific and Indian ocean regions, and proposed a global ENSO sequence to be compared with his "regional" (= South American) El Niño sequence (see Fig. 1, left column).

Quinn's sequences have been considered the major reference for most studies of variability in ENSO recurrence and intensity throughout the last four and a half centuries. However, a close re-examination of the same documentary data used by Quinn, and/or additional documents, from Peru, showed that serious doubts must be expressed regarding the real occurrence of a number of these reconstructed EI Niño events (Ortlieb, 2000). In some cases, there were misinterpretations of written data or problems of unreliability of the sources used by Quinn. In other cases, strong documentary evidence from northern Peru and southern Ecuador contradicts the reconstruction of so-called El Niño events (see below). Additionally, in numerous instances, Quinn interpreted occurrences of EI Niño events solely from information on heavy rainfalls in central or southern Peru, or in Bolivia (Potosi), or from a single source. These are areas where precipitation excess cannot be reliably linked to EI Niño conditions even in the modern instrumental period.

\section{Western South America: a key region for ENSO reconstructions} The Pacific coast of South America is undoubtedly a key area for paleoENSO studies, both because of the availability of written records since 1525 AD and because of the strong impact of the ENSO phenomenon in two specific regions.

Analyses of instrumental data of the $20^{\text {th }}$ century confirm that the positive rainfall anomalies over the coastal regions of Ecuador and northern Peru 


\section{Science Highlights}

show the only statistically significant correlation with EI Niño events within the whole region encompassing Ecuador, Peru and Bolivia (Aceituno, 1988; Rome Gaspaldy and Ronchail, 1998; Ronchail; 1998; Rossel et al., 1998). Assuming that this relationship could be extrapolated into the past, Ortlieb (2000) proposed that positive rainfall anomalies could be used as a major criterion for the reconstruction of former ENSO events. Accordingly, written records on high rainfalls in any given year would support the interpretation of former El Niño conditions, and inversely, reports on drought would be interpreted as normal (or La Niña) conditions. These same criteria are currently being used by Ortlieb and Hocquenghem (in prep.) for an up-dated sequence of El Niño occurrences from Peruvian documentary data (Fig. 1, column 2). For a better assessment of the reconstructed past El Niño events, emphasis is given to the multiplicity of converging reports covering an area extending from Guayaquil to Trujillo (bars in violet in Fig. 1 Column 2).

In central Chile, a well-established correlation links positive (negative) rainfall anomalies and El Niño (La Niña) events (Rutllant and Fuenzalida, 1991). $80 \%$ of the total annual rainfall over Santiago $\left(33^{\circ} \mathrm{S}\right)$ occurs during austral winter. Significant positive winter rainfall anomalies are produced during the development phase of EI Niño events, contemporaneous with the weakening of the Pacific Subtropical Anticyclone (PSA), i.e. negative values of the Southern Oscillation Index (SOI), and with other synoptic anomalies. Inversely, negative rainfall anomalies and severe droughts are well correlated with La Niña events and a strong PSA (Rutllant and Fuenzalida, 1991) (Fig. 2). Thus, the relationship between rainfall anomalies over this region and ENSO seems strong enough to enable reconstructions of past events. The advantage of this region over northern Peru is that La Niña events may be inferred from drought data.

From the point of view of historical climate studies, it is clear that written reports constitute a

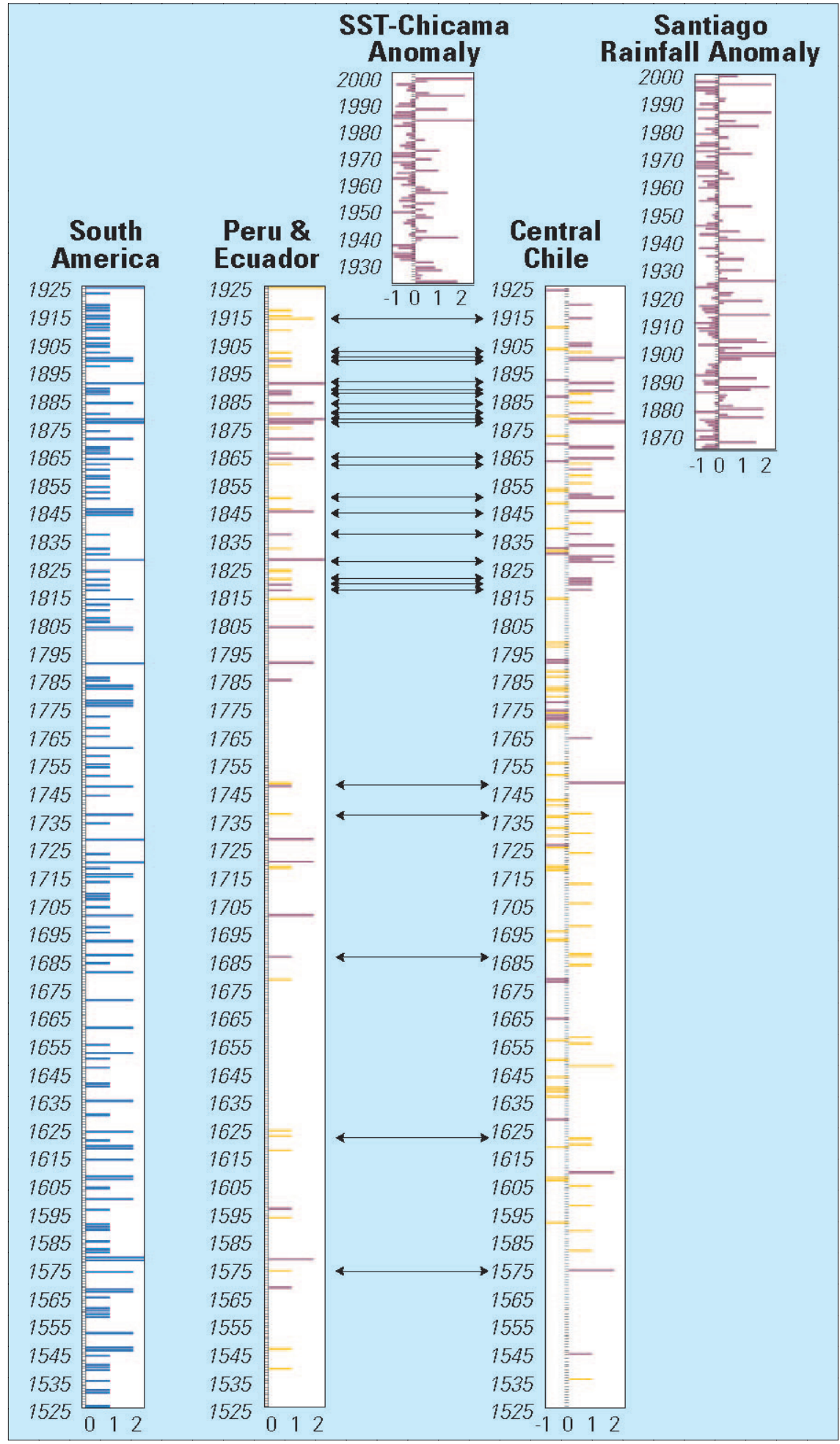

Fig. 1: Comparison between historical sequences of ENSO events, reconstructed from documentary data from the whole of South America (Quinn, 1993), Ecuador/Northern Peru (Ortlieb, 2000; Ortlieb and Hocquenghem, in prep.) and Central Chile (Ortlieb, in prep.). For the historical sequences: -1: La Niña events (only for Central Chile), 0: normal years (or lack of relevant data), 1, 2 and 2.5: weak and moderate, strong, or very strong El Niño events, respectively. Yellow bars correspond to less robust data. Horizontal arrows indicate the coeval El Niño related conditions in Central Chile and Ecuador/Northern Peru. Standardized anomalies of the mean (February-May) SST, at Puerto Chicama (northern Peru) for the period 1925-1998 and annual rainfall at Santiago (central Chile) for the period 1866-2000 both correlate significantly with ENSO.

valuable data base, extending back to the early $16^{\text {th }}$ century. In the arid regions of coastal Peru and southern Ecuador, as in the areas dedicated to agricultural activities (central Chile), the amount of precipitation and the occurrence of river floods were commonly reported or referred to in several kinds of documents. In Santiago, the droughts gave rise to 


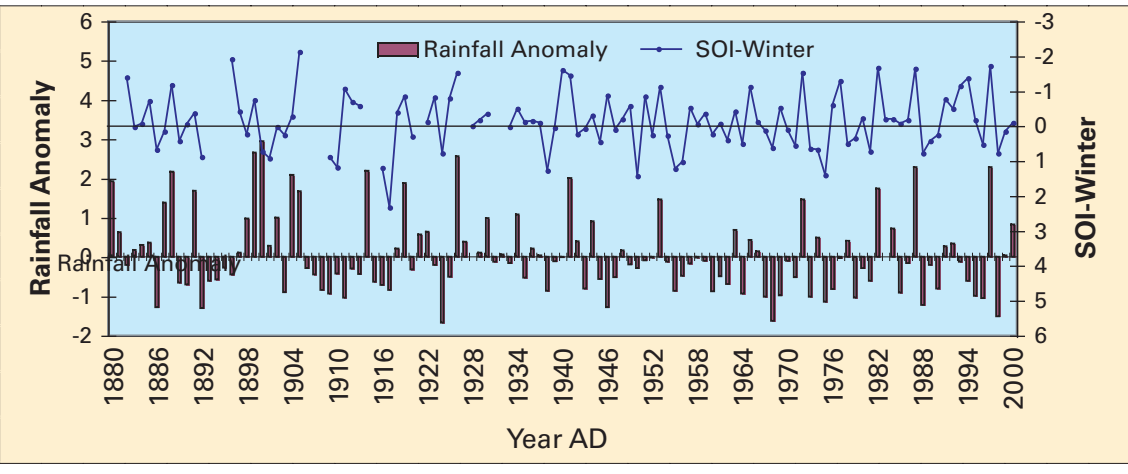

Fig. 2: Comparison between the standardized anomaly of annual rainfall at Santiago and the mean SOl for the austral winter (May to August). The two series are significantly correlated $(r=-0.5, p<0.01)$

"rogativas" (processions organized by the Church to implore the Virgin and the saints to provoke rainfall) that were systematically discussed in the "Cabildo" (town hall) and reported in its official records. Thus, in areas largely influenced by the ENSO system we can fortunately rely upon relevant documentary reports.

\section{From colonial written data to the reconstruction of El Niño events}

In the area of Ecuador under the influence of ENSO conditions (between Manta, Guayaquil and the Peruvian border) documentary records are relatively scarce. In the case of Peru, the key area for the most reliable El Niño impacts (Piura andTrujillo provinces) lies far away from Lima, the center of colonial life, and only discontinuous chronicles and anecdotal data are available. Ironically, the destruction of municipal archives in northern Peru was due to several floods produced during strong El Niño years. Unfortunately, the relatively abundant information on climate anomalies in Lima and on the Rimac River floods are of limited interest because they do not necessarily reflect $\mathrm{EI} N$ iño conditions (Ortlieb, 2000).

In Chile, the longest available chronicle of weather anomalies is that of Santiago ("Actas del Cabildo"). This is most fortunate since this almost uninterrupted documentary database is located in the center of the zone of maximum impact of ENSO conditions. In northern Chile, reports on climate anomalies can also be used for the reconstruction of El Niño (rainfall excess in coastal areas) or La Niña episodes (strong rainfalls in the Chilean altiplano). The identification of former $\mathrm{El}$ Niño in coastal areas of southern Ecuador and northern Peru, and in central Chile, is thus primarily based on written reports of rainfall excess and of associated manifestations (river floods, bridge destruction, agricultural consequences). In some cases additional information, such as reports of warmer air (or sea) temperature, sudden fish mass-mortality, anomalous wind patterns, may also be relevant. The intensity of the catastrophic impacts and their geographical extension help to evaluate the strength of the former events. Because of the general aridity along the coast of Peru and southern Ecuador, it is only from the central Chile record that La Niña events can be reliably reconstructed (Fig. 1, column 4).

Unlike Quinn, we rely only upon reports from independent eyewitnesses (or, at least, first informants), disregarding any secondary (or tertiary) sources.

\section{Comparison of the regional historical El Niño sequences}

Comparison of the three historical sequences shown in Fig. 1 leads to the following conclusions:

- The "South America" sequence includes most of the reconstructed events of columns 2 and 3 (plus a few events inferred from data from Bolivia and Brazil). This "aggregating" approach tends to increase the number of reconstructed former El Niño events and implies the existence of dynamically implausible sub-regional manifestations of ENSO.
- The lower number of EI Niño events recorded in Ecuador/Peru and central Chile during the $16^{\text {th }}$ to $18^{\text {th }}$ centuries is partly due to differences in the availability and reliability of the documentary data, as compared to the $19^{\text {th }}$ century. However, it is inferred that a real increase in the frequency and intensity of events did occur in the $19^{\text {th }}$ and $20^{\text {th }}$ centuries.

- A good correlation is observed between the documented records of Ecuador/Peru and Chile after 1817. This tendency is confirmed by agreement with instrumental data during the $20^{\text {th }}$ century.

- Prior to 1817 the two records are overwhelmingly discrepant: a very limited number of events were coincidentally reconstructed in the two areas. This lack of correlation between the two series cannot be assigned solely to a lack of information, because in many cases available data in one region points to normal or La Niña conditions, while El Niño manifestations are recorded in the other area. This implies a change in ENSO related teleconnection patterns occurred abruptly around 1817.

- The lack of correlation between the two records is independent of the strength of the reconstructed events. The strongest (and better documented) reconstructed events do not show a better correlation than episodes of minor intensity. This evidence supports the conjecture that the teleconnection pattern observed in the last two centuries was different in earlier times.

\section{Toward a robust sequence of El Niño events}

The consolidation of a single, robust chronological sequence of EI Niño occurrences in South America, will involve further investigations in the following directions:

- Development of systematic documentary studies for all the years subject to El Niño conditions in core regions, as well as less well studied regions known to be influenced by the ENSO system. This may include the Nordeste of Brazil, as well as central Chile and southern Ecuador/ northern Peru. 


\section{Science Highlights}

- Intercalibration of documentary records from central Chile and annually resolved dendroclimatic data from both Chile and Argentina.

- Modeling of the dynamics of regional atmospheric circulation pattern that might account for changes in the ENSO teleconnection system at interannual to interdecadal time scales.

\section{REFERENCES}

Aceituno, P., 1988: On the functioning of the Southern Oscillation in the South American sector. Part 1: surface climate. Mon. Wea. Rev., 116: 505-524.

ORTLEB, L., 2000: The documentary historical record of El Niño events in Peru: An update of the Quinn record (sixteenth through nineteenth centuries). In El Niño and the Southern Oscillation: Variability, Global and Regional Impacts, H. Diaz \& V.

Markgraf (Eds.), Cambridge University Press. Cambridge.p. 207-295

Quinn, W.H., 1993: The large-scale ENSO event, the El Niño, and other important features. Bull. Inst. Franç. Et. Andines, 22 (1), pp. 13-34.
Quinn, W.H Neal, VT. and Antunez de Mayolo, S. 1987: El Niño occurrences over the past four and a half centuries. Journal of Geophysical Research 93(Cl3), pp. 14449-14461.

QuINN, W.H. and NEAL, V.T., 1992: The historical record of El Niño events. In Climate since A.D. 1500. R.S Bradley \& P.D. Jones (eds.), London; Routledge, pp. 623-648.

For full references please consult:

www.pages-igbp.org/products/newsletters/ref2002_3.html

\section{Summer and Winter Temperature Reconstructions in Japan}

\section{TAKeHIKo MiKami}

Department of Geography, Tokyo Metropolitan University, Tokyo 192-0397, Japan; mikami@comp.metro-u.ac.jp

In Japan, a great number of weather diaries from most parts of the country are preserved in local libraries and museums (Fig. 1). Some outstanding official diaries have been kept continuously since the seventeenth century. Over the last few decades, most of the known daily weather records were digitized and added to the Historical Weather Database of Japan (e.g., Mikami 1988 and 1999). Another valuable source for historical climatology in Japan is the freezing date record of Lake Suwa (central Japan). These dates were systematically recorded from the fifteenth century onwards. In this paper, we explain how summer and winter temperatures were estimated, based on a century long weather diary and the half millennial Lake Suwa record.

The reconstruction of summer (JJA) temperatures draws on the monthly number of rainy days in Tokyo from 1721, which were obtained from the "Ishikawa diaries" (Mikami, 1996). Initially, the data

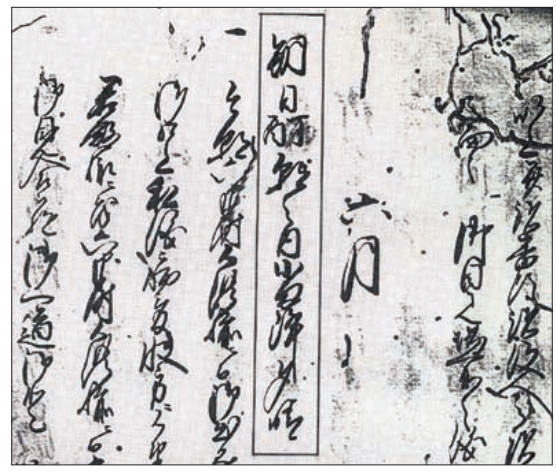

Fig. 1: An example of a weather diary from Japan, $18^{\text {th }}$ century. Daily weather conditions are described in detail. The boxed area says "a little rainfall in the morning, but became fine in the evening."

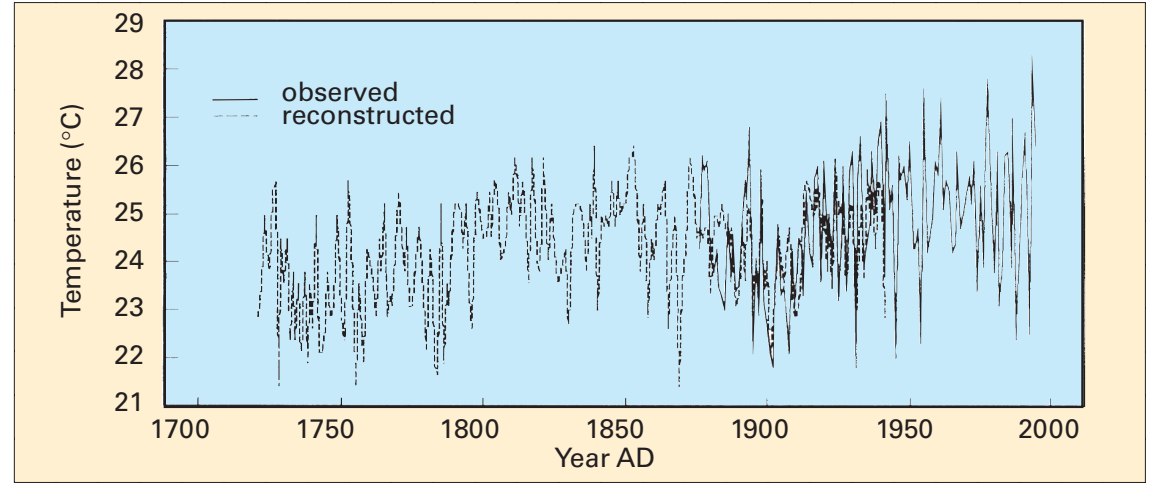

Fig. 2: July temperature variations in Tokyo for 1721-1995.

were calibrated with the long temperature series of Tokyo over the period from 1876 to 1940, using linear regression techniques. It turns out that the correlation between the monthly number of rainy days and mean monthly temperatures was highest for July ( $r=-0.70$, significant at $1 \%$ level). This is related to the prevailing weather situations. Under the influence of a strong subtropical anticyclone, July is hot and dry, whereas stagnant polar fronts and passing extratropical cyclones are associated with cool and rainy weather situations. Consequently, July temperatures were estimated from the recorded number of rainy days for the period 1721 to 1875 , using a regression equation. Finally, the estimated temperatures were used to extend the instrumental series of Tokyo (1876 to 1995) back to 1721 (Fig. 2).

Long temperature trends can be explained using weather diaries, as in Figure 1. From 1721 to 1790 , July temperatures were about 1 to $1.5^{\circ} \mathrm{C}$ lower than the 1961-1990 mean. During this period of cool summers, July temperatures displayed a large year- to-year variability. Cold summers were registered in 1728, 1736, 1738, 1755, 1758, 1783, 1784 and 1786. During the 1780's severe famine occurred repeatedly. On the other hand, many warm summers stand out in the record for the nineteenth century, in particular in the 1810s and from 1851 to 1853. July was again remarkably cool around 1900 . This observation is clearly captured by both estimated and measured temperature series.

The reconstruction of winter temperatures is based on the Lake Suwa record. When the lake froze, shrinkage and expansion of the ice sheet due to diurnal temperature variations caused an ice cracking phenomenon called "Omiwatari," which was said to resemble "a bridge crossing the lake" (Fig. 3). The ancient village people might have believed it to be the track of a god visiting a goddess on the opposite shore. Since the fifteenth century, the formation of "Omiwatari" has been celebrated in a ceremony a couple of days after its occurrence. The dates of "Omiwatari" have been recorded by the Suwa shrine since the $15^{\text {th }}$ century, 